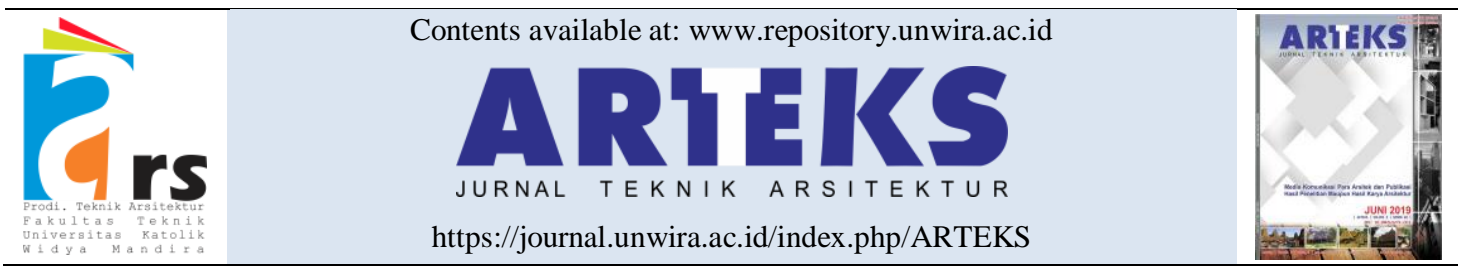

Editorial paper

doi: http://doi.org/10.30822/arteks.v5i1.378

\title{
Teori dalam penelitian arsitektur
}

\author{
Iwan Sudradjat
}

\author{
Advisor ARTEKS : Jurnal Teknik Arsitektur \\ Guru Besar dalam bidang Sejarah, Teori dan Kritik Arsitektur, Sekolah Arsitektur, \\ Perencanaan dan Pengembangan Kebijakan, Institut Teknologi Bandung \\ Email: iwansudr@itb.ac.id; iwansudr@gmail.com
}

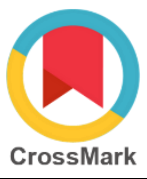

\section{Peran teori}

"Teori" merupakan terminologi yang maknanya jarang dipahami dengan benar oleh para mahasiswa, dosen dan bahkan peneliti sekalipun. Gambaran mental yang mereka miliki tentang teori adalah sesuatu yang abstrak, mengawang-awang, rumit, oleh karena itu dianggap sebagai hal yang patut dihindari. Seorang sosiolog terkenal Ian Craib (1984) dengan tepat memberikan gambaran tersebut:" The very word "theory" sometimes seems to scare people ... (Only) few people feel at home with theory or use it in a productive way".

Tidak dapat dibantah, teori mempunyai kedudukan yang sangat penting dalam penelitian di bidang ilmu apapun, termasuk penelitian di bidang arsitektur. Teori berperan untuk menjelaskan keterkaitan antara suatu fenomena dengan data empiris yang diamati dan dianalisis secara sistematis oleh peneliti. Kerlinger (1973) mendefinisikan teori sebagai" seperangkat konsep, definisi dan proposisi yang menyajikan gambaran sistematik tentang suatu fenomena beserta hubungan di antara variabelvariabelnya, dengan tujuan memberi penjelasan atau memprediksi tentang fenomena tersebut".

Lebih lanjut Neuman (2003) menjelaskan bahwa teori memiliki peran penting dalam mengkaitkan suatu hasil penelitian dengan sejumlah pengetahuan relevan yang telah disumbangkan oleh para peneliti sebelumnya, sehingga melalui penelitiannya seorang peneliti tidak hanya mampu melihat sebatang pohon, tetapi sebuah hutan yang dipenuhi dengan banyak pohon. Teori dengan kata lain berperan meningkatkan kesadaran peneliti terhadap interkonektisitas di antara data dan hasil penelitian.

Sayangnya banyak peneliti yang tidak mampu secara eksplisit menentukan teori mana yang sesuai dengan penelitiannya, dan bagaimana teori tersebut harus digunakan. Sebagai akibatnya mereka cenderung menjadi peneliti yang a-teoretis dan perannya hanya terbatas pada kolektor data empiris.

Untuk meneliti tentang makna dalam arsitektur misalnya, seorang peneliti secara eksplisit harus menetapkan alternatif teori mana yang paling relevan baginya di antara sekian banyak teori yang telah berkembang, apakah teori strukturalisme, fenomenologi, pasca strukturalisme atau teori lainnya.

\section{Fungsi teori}

Teori memiliki fungsi yang sangat penting dalam penelitian, yaitu memberikan kerangka konseptual yang terstruktur dan koheren, sehingga peneliti dapat memahami fenomena yang diteliti dalam perspektif yang benar. Berdasarkan kerangka tersebut peneliti akan dapat mendefinisikan permasalahan penelitian, mengidentifikasikan variabel dan hubungan antara variabel penelitian, merumuskan hipotesis, mengorganisasikan data dan menjembatani celah-celah inkonsistensi antar data yang tersedia, menafsirkan data, serta melakukan proses sintesis dan generalisasi hasil penelitian.

Dengan demikian, teori memberikan landasan berpijak yang kokoh serta panduan untuk melakukan kegiatan yang terarah kepada peneliti, sehingga peneliti mampu meningkatkan kualitas dan argumentasi 
hasil penelitiannya. Dengan bantuan teori peneliti tidak berhenti pada deskripsi empiris semata, ia bisa beranjak ke uraian eksplanatori, bahkan hingga ke kritik atas teori yang digunakan serta saran tentang arah penelitian dan pendekatan konseptual selanjutnya.

\section{Kriteria teori}

Seperangkat gagasan dapat diterima sebagai teori apabila memenuhi dua kelompok kriteria, yaitu:

(1) Kriteria Ideal

Gagasan-gagasan tersebut harus:

a. mempunyai hubungan yang logis dan konsisten, serta tidak memiliki kontradiksi internal

b. saling berkaitan satu dengan lain

c. membentuk pernyataan-pernyataan (statements) yang tuntas, yang diperlukan untuk menerangkan berbagai sifat fenomena yang diselidiki

d. mengandung proposisi-proposisi yang jelas, tidak tumpang tindih atau berulang

e. dapat diujikan secara empiris

(2) Kriteria Pragmatis

Gagasan-gagasan tersebut harus memiliki komponen utama sebagai berikut:

a. asumsi-asumsi

b. paradigma untuk mengidentifikasikan aspek-aspek realitas yang akan diujikan secara empiris

c. konsep-konsep

d. variabel-variabel

e. proposisi-proposisi

f. hubungan yang sistematis dan bersifat kausal antara konsep dan proposisi tersebut

Karena asumsi, paradigma dan konsep tidak dapat diujikan langsung secara empiris, maka perlu dioperasionalisasikan ke dalam bentuk variabel dan proposisi. (Gambar 1)
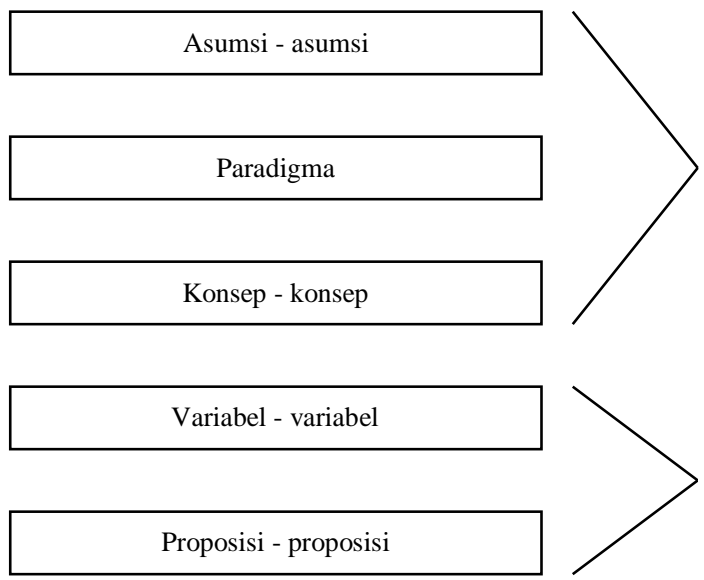

Tidak dapat diujikan

langsung secara empirik

\section{T E O R I}

Gambar 1. Komponen utama teori

Teori yang baik harus memenuhi prinsip parsimony (simpler is better). Dengan kata lain, teori yang baik adalah teori yang diungkapkan secara sederhana, ringkas, tepat, tetapi mampu menjelaskan fenomena secara memadai. Teori yang baik adalah teori yang bersifat komprehensif tetapi tidak perlu dicirikan oleh kompleksitas yang berlebihan.

Perlu disadari bahwa teori senantiasa bersifat provisional. Tidak ada satu teoripun yang mampu menjelaskan suatu fenomena secara sempurna sepanjang masa. Teori menawarkan penjelasan atau jawaban yang bersifat parsial atau tentatif, dan selalu memiliki ketidakpastian dan celah 
ketidaksempurnaan. Teori-teori baru selalu berkembang dari waktu ke waktu untuk menyempurnakan kekurangan atau kelemahan yang ditemukan dalam teori yang telah ada sebelumnya.

Teori tidak dinilai berdasarkan kriteria benar dan salah, tetapi berdasarkan kemanfaatannya. Kemanfaatan suatu teori bisa berkurang akibat perubahan fenomena di lapangan atau akibat perkembangan pengetahuan baru, sehingga dari waktu ke waktu teori harus selalu diperbaharui. Dengan demikian, teori selalu bersifat open ended dan berusaha bertumbuh-kembang ke tingkat yang lebih tinggi.

\section{Paras dan fokus teori}

Paras suatu teori sangat ditentukan oleh rentang fenomena yang ingin dijelaskannya. Dikenal ada tiga jenis paras teori, masing-masing dengan karakteristik sebagai berikut:

1) Teori Paras Mikro:

a. Berkepentingan dengan peristiwa pada paras mikro

b. Mencakupi penggalan ruang dan waktu serta jumlah manusia yang terbatas

c. Menggunakan konsep-konsep yang tidak terlalu abstrak

Contoh: Pengaruh tata letak terhadap interaksi murid dalam kelas

2) Teori Paras Meso:

a. Beroperasi pada paras menengah (intermediate)

b. Mencoba menjembatani kesenjangan antara teori paras makro dan mikro

Contoh: Teori tentang territorialitas (Habraken), sense of place (David Canter), defensible space (Oscar Newman)

3) Teori Paras Makro:

a. Berkepentingan dengan peristiwa dalam agregat makro

b. Menggunakan konsep-konsep yang abstrak

Contoh: Teori relativitas Einstein

Berdasarkan fokusnya, teori dapat dibedakan menjadi teori formal dan teori substantif. Teori substantif biasanya dikembangkan untuk area yang sangat spesifik (contoh: Teori tentang privacy, personal space, crowding), sementara teori formal untuk area konseptual yang lebih luas dan umum (contoh: Teori tentang environment and culture Amos Rapoport, environment and behaviour Gary Moore). Dalam praktek, suatu penelitian seringkali tidak bisa didasarkan hanya pada teori formal atau teori substantif semata, tetapi pada gabungan di antara keduanya.

\section{Memverifikasi vs membangun teori}

Dalam kaitannya dengan teori, penelitian pada hakekatnya dapat dibedakan menjadi penelitian untuk memverifikasi teori (theory verification, theory first) dan penelitian untuk membangun teori (theory generation, theory after).

Penelitian kuantitatif biasanya dimulai dengan suatu teori (theory first), kemudian dilanjutkan dengan perumusan hipotesis berdasarkan teori tersebut serta penyusunan rancangan penelitian untuk memverifikasi hipotesis. Oleh karena itu penelitian kuantitatif disebut juga sebagai theory verification research atau penelitian dengan pendekatan deduktif. (Gambar 2) 


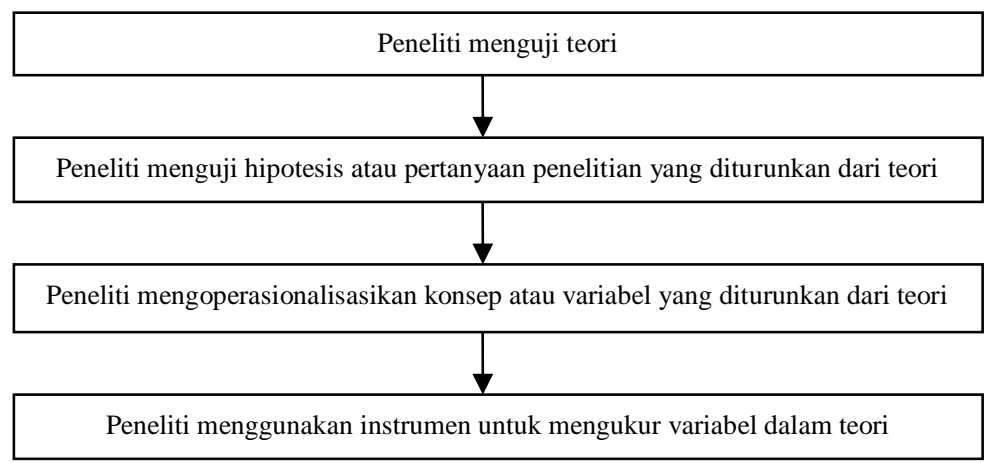

Gambar 2. Penelitian utnuk memverifikasi teori (deduktif)

Creswell (1994: 88)

Penelitian kualitatif atau grounded theory dimulai dengan pengumpulan informasi lapangan tanpa kerangka yang terstruktur. Berdasarkan informasi yang diperoleh sesuai kaidah penelitian kualitatif, peneliti kemudian menyusun suatu teori yang dapat menjelaskan atau memberikan pemahaman atas fenomena yang terjadi di lapangan (theory after). Oleh karena itu penelitian kualitatif atau grounded theory disebut juga sebagai theory generation research atau pendekatan induktif. (Gambar 3)

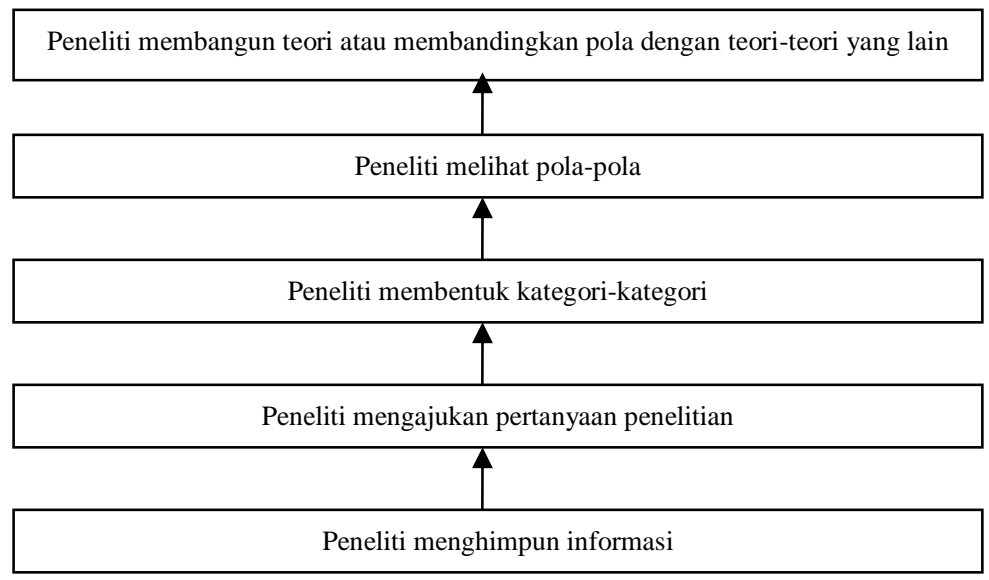

Gambar 3. Penelitian utnuk memverifikasi teori (induktif) Creswell (1994: 96)

Theory verification research dan theory generation research keduanya diperlukan dan mempunyai kedudukan yang sama, tergantung pada tujuan dari penelitian, konteks permasalahan yang akan diteliti, dan ketersediaan kerangka teoritis dan pengetahuan yang telah ada sebelumnya di bidang terkait. Dalam kasus di mana diperlukan pengujian atas keberlakuan suatu teori atau penyempurnaan atas suatu teori, maka peneliti akan memilih theory verification research. Sebaliknya, dalam kasus di mana diperlukan area penelitian yang baru atau konstruksi teori yang baru untuk menjelaskan suatu fenomena, maka peneliti akan memilih theory generation research.

\section{Teori dan metodologi}

Teori biasanya memberikan deskripsi atau prediksi tentang suatu fenomena empirik dalam rumusan yang bersifat umum, tidak secara spesifik mengindikasikan bagaimana cara untuk memverifikasikan. Adalah tugas dari metodologi penelitian untuk mencarikan cara ilmiah paling tepat untuk mengujikan klaim yang diajukan oleh suatu teori. Peneliti harus berusaha mencari kecocokan (good fits) antara teori dan 
strategi penelitian yang akan digunakan untuk pengujian. Sebagai contoh, teori relativitas Einstein hampir tidak mungkin diujikan melalui strategi penelitian kualitatif, dan hanya mungkin untuk diujikan melalui strategi penelitian eksperimental menggunakan alat particle accelerators, dengan frekuensi pengujian ribuan kali.

Agar dapat dengan mudah mencari kecocokan antara teori dan strategi penelitian, seorang peneliti perlu memiliki wawasan dan pengetahuan yang lengkap tentang keterkaitan antara landasan filosofis yang melandasi teori, rumusan teori, dan strategi serta taktik penelitian yang relevan untuk pengujian teori tersebut. (Gambar 4)

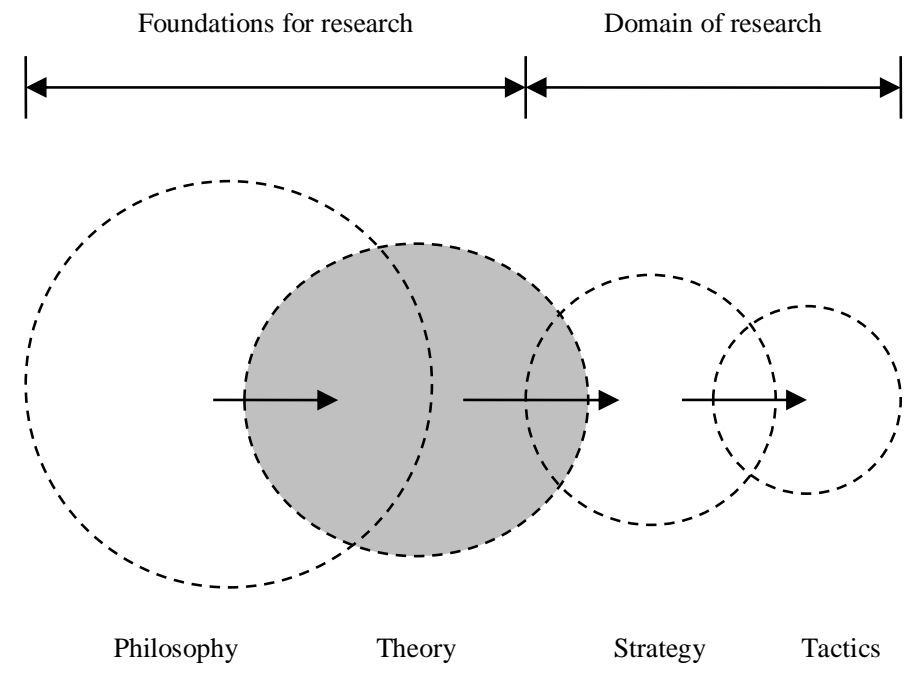

Gambar 4. Philosophy $=$ theory $=$ method chart

Groat \& Wang (2002: 87)

\section{Model}

Untuk dapat menjelaskan teori secara matematis, visual atau grafis, peneliti dapat menggunakan model, yaitu konseptualisasi sistematik tentang teori dalam bentuk skematik. Penggunaan model memiliki aspek positif maupun negatif.

1. Aspek positif:

a. model secara cepat dapat memberikan gambaran tentang suatu teori

b. model menunjukkan secara jelas batas atau limitasi konseptual suatu teori

c. model membantu memahami secara tepat hubungan antara variabel

2. Aspek negatif:

a. model umumnya merupakan simplifikasi dari teori yang diterangkannya

b. model tidak mampu memberi gambaran eksplisit tentang teori secara utuh

c. model memberi kesan adanya urutan waktu di antara variabel

d. model memberi kesan seolah seluruh dimensi logis teori telah tercakup di dalamnya

e. model memberi kesan bahwa variabel-variabel selalu memiliki kecocokan dengan realitas empiris

f. model seringkali menimbulkan salah tafsir

Bila digunakan dengan tepat dan penuh kehati-hatian, model akan sangat membantu peneliti untuk menjelaskan tentang teori, konsep abstrak yang digunakan, serta hubungan antara variabel yang seringkali sulit untuk dijelaskan hanya dengan narasi atau teks. 


\section{Penutup}

Kendala dan aversi terhadap teori yang dialami para peneliti umumnya diakibatkan oleh beberapa hal, yaitu:

a. Perbendaharaan literatur yang buruk, akibat kurangnya akses peneliti terhadap bahan pustaka dan lemahnya dorongan motivasi untuk menelusuri bahan pustaka;

b. Penguasaan atas teori kurang memadai, akibat keterbatasan dasar pemahaman teoretik dan kemampuan linguistik dari peneliti;

c. Keraguan peneliti dalam memutuskan alternatif teori yang relevan bagi penelitiannya, akibat kurangnya wawasan tentang cara kreatif untuk menggunakan teori tersebut.

Selama kendala dan sikap aversi tersebut belum bisa diatasi, maka mutu penelitian dalam bidang arsitektur di Indonesia sulit untuk ditingkatkan.

Meski teori sulit untuk dipelajari dan pencarian teori yang tepat seringkali menimbulkan frustasi, teori merupakan bagian inti dari kegiatan keilmiahan penelitian yang terlalu penting untuk diabaikan. Oleh karena itu tidak ada pilihan lain bagi peneliti selain menghadapi tantangan tersebut dengan penuh semangat dan kesungguhan.

ARTEKS : Jurnal Teknik Arsitektur, volume 5 nomor 1 edisi April 2020 ini menampilkan 12 artikel ilmiah dengan topik pembahasan yang cukup beragam, yang dapat dikelompokkan ke dalam tiga isu besar, yaitu: Pertama, tentang aspek-aspek dalam desain arsitektur bangunan; Kedua, tentang tradisi dan unsur arsitektur tradisional; Ketiga, tentang dinamika ruang kota dan amenitasnya.

Dalam kelompok isu pertama, Andrew Cokro Putra, et al membahas tentang strategi adaptasi arsitektur; Nabila Qirala Sukada, et al membahas tentang ekspresi arsitektur; Efraim Desprinto Lalu, et al membahas tentang akulturasi arsitektural; dan Syamsun Ramli, et al membahas tentang estetika elemen arsitektur.

Dalam kelompok isu kedua, Asta Juliarman Hatta, et al membahas tentang tradisi membangun rumah tradisional; Widianingtias, et al membahas tentang unsur arsitektur rumah tradisional; dan Cahyo Septiono Hutomo, et al membahas tentang mitigasi bencana pada kampung budaya.

Dalam kelompok isu ketiga, Alifi Diptya Nidikara, et al membahas tentang dinamika perubahan, transformasi, dan permanensi lingkungan; Grace Putri Dianty, et al membahas tentang aktivitas di ruang terbuka publik; Frengky Benediktus Ola, et al membahas tentang peredam kebisingan pada lingkungan hunian; Paulus Bawole membahas tentang kampung kota sebagai tujuan wisata; dan Alfred Wijaya, et al membahas tentang kriteria desain jalur pedestrian.

ARTEKS : Jurnal Teknik Arsitektur berkomitmen untuk meningkatkan bobot keilmiahan artikel yang dipublikasikan secara berkelanjutan, melalui proses blind review yang ketat oleh pakar bidang ilmu terkait, agar secara gradual karya tulis ilmiah yang dipublikasikan semakin bermutu, dan kesadaran akan pentingnya teori dalam penelitian arsitektur semakin meningkat, sehingga dapat diapresiasikan oleh komunitas akademik arsitektur di Indonesia secara luas.

\section{Referensi}

Craib, Ian (1984), Modern Social Theory: From Parsons to Habermas, St. Martin's Press.

Creswell, John W (1994), Research Design: Qualitative \& Quantitative Approaches, Sage Publications, Inc.

Groat, Linda and Wang, David (2002), Architectural Research Methods, John Wiley \& Sons, Inc.

Kerlinger, F.N. (1973), Foundations of Behavioral Research, Holt, Reinhart and Winston.

Neuman, W. Laurence (2003), Social Research Methods: Qualitative and Quantitative Approaches, Fifth Edition, Pearson Education, Inc.

Snyder, James C (1984), Architectural Research, Van Nostrand Reinhold Company. 